\title{
SISTEMA DE AVALIAÇÃo DE PERIÓDICOS NO BRASIL: IMPACTOS DA EVOLUÇÃO DOS CRITÉRIOS DO QUALIS-PERIÓDICOS DA ÁREA DE EDUCAÇÃ̃O
}

\author{
SYSTEM OF EVALUATION OF JOURNALS IN BRAZIL: IMPACTS OF THE \\ EVOLUTION OF THE QUALIS-PERIÓDICOS CRITERIA IN THE AREA OF \\ EDUCATION
}

\section{SISTEMA DE EVALUACIÓN DE REVISTAS EN BRASIL: IMPACTOS DE LA EVOLUCIÓN DE LOS CRITERIOS QUALIS-PERIÓDICOS EN EL ÁREA DE EDUCACIÓN}

Laís Zaccaro Sene ${ }^{1}$ 0000-0001-7297-6262 José Luís Bizelli² 0000-0002-6634-1444

\author{
${ }^{1}$ Universidade Estadual Paulista - Araraquara, São Paulo, Brasil; lzsene@unesp.br \\ ${ }^{2}$ Universidade Estadual Paulista - Araraquara, São Paulo, Brasil; jose.bizelli@ unesp.br
}

\section{RESUMO:}

O artigo analisa a produção do Qualis-Periódicos da área de Educação, no período de 2010 a 2018 - triênio 2010 a 2012; quadriênio 2013 a 2016 e avaliação de meio termo sobre os anos 2017 e 2018. O instrumento serve para avaliar a produção de docentes do Sistema de Pósgraduação no Brasil, embora seja frequentemente utilizado para outros fins. É possível determinar dois tipos de mudança nos critérios de avaliação: uma incremental, entre o triênio e o quadriênio; outra de ruptura, quando em 2019, na avaliação de meio termo, introduz-se um novo fator para medir impacto ou citação. As análises da pesquisa estão fixadas sobre fontes documentais: os próprios Qualis e os documentos orientadores e avaliativos da Área da Educação. Os dados demonstram um aumento considerável na estratificação dos periódicos ocasionada pela objetivação dos critérios, nos primeiros períodos, e uma ruptura no último; uma diminuição drástica do universo de avaliação com a introdução do princípio de área mãe; e uma incerteza quanto à avaliação que virá em 2021.

Palavras-chave: qualis-periódicos; produção científica; sistema de avaliação.

\begin{abstract}
:
The present article analyzes the production of the Qualis-Periódicos in Education, in the period from 2010 to 2018 - triennium 2010 to 2012; quadrennium 2013 to 2016 and mid-term evaluation on the years 2017 and 2018. The instrument serves to evaluate the production of faculty members of the Graduate System in Brazil, although it is often used for other purposes. It is possible to determine two types of change in the evaluation criteria: either incremental, between the triennium and the quadrennium; or disruptive, wherein in 2019, in the mid-term evaluation, a new factor is introduced to measure impact or citation. The research analyses are based on documental sources: the Qualis itself and the guiding and evaluative documents of the education area. The data show a considerable increase in the stratification of the journals caused by the objectification of the criteria in the first periods and a rupture in the last one; a drastic decrease of the evaluation universe with the introduction of the concept of parent area; and an uncertainty about the evaluation that will come in 2021.
\end{abstract}

Keywords: qualis-periódicos; scientific production; evaluation system. 


\section{RESUMEN:}

El artículo analiza la producción del Qualis-Periódicos del área de Educación, en el período desde 2010 hasta 2018 - trienio 2010 hasta 2012; cuadrienio 2013 hasta 2016 y evaluación del medio término sobre los años 2017 hasta 2018. El instrumento sirve para evaluar la producción de docentes del Sistema de Posgrado en Brasil, aunque se utilize frecuentemente para otras finalidades. Es posible determinar dos tipos de cambios en los criterios de evaluación: una incremental, entre el trienio y el cuadrienio; otra de ruptura, cuando en 2019, en la evaluación del medio término, se introdujo un nuevo factor para mensurar impacto o citación. Los análisis de la investigación están fijados sobre fuentes documentales: el propio Qualis y los documentos orientadores y evaluativos del Área de Educación. Los datos demuestran un incremento considerable en la estratificación de las revistas científicas ocasionada por la objetivación de los criterios, en las primeras revistas científicas, y una ruptura en el último; una disminución drástica del universo de evaluación con la introducción del principio del área madre; y una incertidumbre en lo que respecta a la evaluación que se llevará a cabo en 2021.

Palabras clave: qualis-periódicos; producción científica; sistema de evaluación.

\section{Introdução}

O Qualis-Periódicos é muito mais do que um portal organizado pela Coordenação de Aperfeiçoamento de Pessoal de Nível Superior (CAPES) para chancelar um ranqueamento nacional de revistas de uma determinada área do conhecimento, já que, ao classificar e valorar os veículos de comunicação científica, passa a ser utilizado para qualificar a produção dos docentes vinculados ao Sistema Brasileiro de Pós-graduação, interferindo diretamente na pontuação quadrienal dos Programas de Pós-Graduação. Assim, os periódicos bem avaliados transferem valor a seus autores, melhorando a nota de seus programas e permitindo maiores recursos de agências financiadoras e melhor autonomia de gestão sobre os gastos realizados.

A CAPES, portanto, cria uma métrica nacional para enfrentar esse quesito específico da avaliação - independente das diferenças regionais ou históricas -, de modo que retorne à sociedade o investimento feito na academia, mediante a indicação dos resultados da Pósgraduação na geração de recursos humanos e no desenvolvimento de novos produtos e processos (MONTEIRO; FURLAN; SUAREZ, 2017).

Contudo, a gestão das revistas frente às métricas adotadas pelo sistema avaliativo - pelo Qualis-Periódicos - tem como resultado um ambiente extremamente competitivo devido à imposição de travas estatísticas que perpetuam desigualdades ou desclassificam periódicos através dos estratos avaliativos fixados, em nome de preservar a qualidade da produção científica nacional e dos veículos científicos, cada vez mais internacionalizados. Por mais que seja possível reconhecer que o Qualis tem sido um dos elementos responsáveis pelo aprimoramento dos periódicos nacionais, o clima competitivo dificulta que as competências da 
equipe editorial estejam totalmente voltadas à seleção e circulação do conhecimento científico relevante produzido na academia ou nos laboratórios e centros de pesquisa.

Tomando a Área de Educação como referência, vários autores têm se debruçado sobre a política de produção do Qualis pela CAPES, enfocando diferentes aspectos: os impactos no processo de gestão editorial de periódicos (SANTOS CRUZ, 2020; PONCE et al., 2017); os indicadores mais adequados à métrica de avaliação (SANTOS CRUZ; SANTOS; BIZELLI, 2019; SOUZA et al., 2018); os efeitos da utilização de um fator de impacto internacionalizado sobre o sistema de pós-graduação (BIZELLI, 2017); o processo de avaliação dos periódicos em estratos específicos e períodos determinados (RIBEIRO; ALENCAR; COUTO, 2016); os contornos e limites do processo Qualis (BARRADAS BARATA, 2016).

O presente artigo, porém, traça uma comparação entre os processos avaliativos que vão de 2010 a 2018 - ou seja, compreende o triênio 2010-2012; o quadriênio 2013-2016 e a avaliação de meio termo que aconteceu em 2019 -, percorrendo indícios que apontem para o motivo das mudanças realizadas nos critérios de classificação e suas consequências para as revistas. Assim, busca entender a tendência em internacionalizar os periódicos brasileiros para consolidar um modelo de política científica, como apontam Frigeri e Monteiro (2014).

Segundo Gil $(2002,2008)$, é possível dizer que a pesquisa é explicativa, ou seja, procura identificar os motivos para a ocorrência dos fatos; de cunho descritivo; e utiliza-se de fontes documentais de informação: documentos oficiais da CAPES (MARCONI; LAKATOS, 2002). A finalidade, portanto, é contribuir para a compreensão, o fortalecimento e o aperfeiçoamento do sistema de avaliação da produção acadêmica, no Brasil, rumo às melhorias que se façam necessárias, sob a ótica discursiva construída pelo presente texto.

\section{Por que avaliar periódicos?}

Entre dezembro de 2019 e novembro de 2020, a produção científica brasileira ultrapassou 275 mil artigos publicados (NATURE INDEX, 2021). Os números agregam um conjunto expressivo de instituições como universidades, centros de pesquisas, com ou sem apoio de agências de fomento, esparramadas em milhares de periódicos científicos que publicizam o conhecimento construído.

Todo esse universo está submetido a regras que medem a regularidade dos veículos de publicação; a normalização dos artigos; a verificação da originalidade da produção, entre outros procedimentos. Avaliar, portanto, faz-se necessário para orientar políticas públicas para o incentivo do setor acadêmico. Contudo, avaliar a produção de conhecimento pode ser abstrato 
e de difícil execução (YAMAMOTO, 2001); ou, ainda, avaliar propicia horizontes diferentes: pode prever punição por ações estratégicas implantadas no passado; mas também pode promover reflexões positivas sobre como agir no futuro, oferecendo estabilidade ao próprio sistema de avaliação, desde que seja visível e permita as correções necessárias para ajustes e melhorias (PONCE et al., 2017).

A garantia de que um trabalho publicado contribua para a construção do conhecimento científico, que siga os métodos de pesquisa reconhecidos em sua execução e que esteja apresentado dentro das normas nacionais ou internacionais de padronização é dada pela confiabilidade e prestígio que a revista alcança no sistema avaliativo, retribuindo ao autor reconhecimento por suas descobertas. É fundamental que o sistema tenha rigor de critérios para aferir a qualidade do veículo científico, muito embora as métricas de avaliação estejam historicamente em constante aprimoramento.

No Brasil, o sistema de avaliação de periódicos é responsabilidade da CAPES, fundação do Ministério da Educação (MEC), que tem entre seus papéis institucionais avaliar, expandir e consolidar a Pós-graduação stricto sensu. Fazem parte das atribuições da CAPES:

- avaliação da pós-graduação stricto sensu;

- acesso e divulgação da produção científica;

- investimentos na formação de recursos humanos de alto nível, no país e exterior;

- promoção da cooperação científica internacional;

- indução e fomento da formação inicial e continuada de professores para a educação básica nos formatos presencial e a distância (BRASIL, 2020).

O Qualis-Periódicos, portanto, é um dos instrumentos de avaliação do Sistema Nacional de Pós-graduação (AZEVEDO; OLIVEIRA; CATANI, 2016), já que é o principal medidor da produção dos docentes que pertencem à Pós-graduação (CAPES, 2021). Por princípio, o Qualis mede a qualidade dos artigos científicos, como foi dito, pelo prestígio do veículo de divulgação usado pelos autores.

A estratificação proposta pela agência foi modificada dentro do período de análise deste artigo. No triênio 2010 a 2012 e no quadriênio 2013 a 2016 os estratos eram: A1; A2; B1; B2; B3; B4; B5 e C, e na avaliação de meio termo (2019) foi utilizada a mesma classificação que orientará o período 2017 a 2020 - a ser publicizada em 2021 -, assim estabelecida: A1; A2; A3; A4; B1; B2; B3; B4 e C. Em verdade, os estratos A1; A2 e B1 do antigo Qualis foram transformados em A1; A2; A3 e A4, enquanto os outros estratos transformaram-se em B1; B2; B3; B4 e C, conforme será percentualmente explicado mais adiante. 
Outra mudança interessante a ser anotada sobre os períodos citados - 2010 a 2016 e 2017 em diante - foi sobre a amostra classificada nas áreas. Fazem parte da amostra analisada pela comissão de cada área de conhecimento todos os periódicos citados pelos professores de Pós-graduação daquela área, no período avaliado . Até 2016, os periódicos tinham Qualis diferentes em diferentes áreas de conhecimento. Depois disso, criou-se o conceito de área-mãe, ou seja, os periódicos seriam analisados na área onde fossem mais citados - esta seria a área mãe do periódico - e esta classificação - Qualis-único - valeria para todas as demais áreas .

É importante reafirmar a necessidade de que os indicadores de qualidade sejam claros e estáveis: no caso da Educação, quanto mais qualitativos - e não quantitativos -, ampliam a possibilidade de diálogo com o Sistema de Avaliação, enfrentando questões como as travas estatísticas (SANTOS CRUZ, 2020). Os resultados da avaliação de um determinado período não funcionam apenas como indicador de prestígio de um veículo, mas transferem prestígio a autores e artigos publicados em revistas de Qualis mais elevado (SILVA, 2009). Segundo Frigeri e Monteiro (2009, p. 311), o Qualis é, cada vez mais, empregado como indicador:

[...] que auxilia na concessão de financiamentos, na inclusão de títulos em bibliotecas e indexadores, na orientação de pesquisadores e leitores durante a escolha de títulos, na submissão de trabalhos e na pesquisa de material bibliográfico, além de estimular os editores a elevar o padrão de qualidade dos seus periódicos.

Outro ponto a ser lembrado é que todas as exigências do Qualis influenciam nos processos de gestão dos periódicos, tanto em suas práticas de produção, como na qualidade da publicação, ou mesmo na busca por atender demandas da indexação, incutindo nos editores padrões para manter a revista em destaque na área. Fora que a manutenção dos critérios do sistema de avaliação da CAPES é instável, o que diminui a colaboração entre editores, pois fomenta um ambiente competitivo (BIZELLI; SANTOS CRUZ, 2016; PONCE et al., 2017).

No Brasil, porém, os periódicos científicos não dispõem das mesmas condições de trabalho e principalmente não possuem os mesmos orçamentos: as Agências de Fomento exigem, por exemplo, que o periódico esteja no topo da classificação para receber recursos, fortalecendo os mais fortes e desincentivando os mais fracos que precisam crescer. A abertura de um diálogo permanente com as agências poderia criar formas de suporte para que as equipes editoriais não se sentissem tão prejudicadas nos processos de avaliação.

A CAPES, por sua vez, minimiza o papel do Qualis no quadro da avaliação científica brasileira, frisando sua origem e função. Esclarece, portanto, que o Qualis não é, por exemplo, um indexador - embora muitos editores queiram ver seus periódicos "indexados" no instrumento avaliativo -, não é uma base bibliométrica, mas diz respeito à produção docente 
nos cursos de Pós-graduação. Assim, não é objetivo do Qualis classificar periódicos, ou atestar sua qualidade e muito menos ser utilizado fora do escopo fixado pelo Sistema de Avaliação da Pós-graduação brasileira.

Como observa Barradas Barata (2016), a submissão de artigos em periódicos considera aspectos relativos à revista, além de seu estrato Qualis, tais como: público-alvo, credibilidade e escopo. Reitera a autora que o Qualis não foi desenvolvido para avaliar o desempenho científico individual de autores - ele não tem a capacidade para tal -, já que foi pensado para avaliar e analisar a produção coletiva de um programa de Pós-graduação. Aponta também que o instrumento de medida é pouco sensível a revistas que alteram seus indicadores de modo acelerado, já que o período de utilização é datado (triênio ou quadriênio), cabendo correções apenas para a próxima avaliação.

Daí o volume de reclamações sobre a falta de diálogo entre CAPES e editores, que normalmente procuram obter melhor classificação a fim de incrementar positivamente sua capacidade de alcançar fontes de fomento. É importante frisar que as Agências de Fomento brasileiras são as primeiras a incentivar este comportamento competitivo ao exigir, com já foi dito, que as revistas agraciadas por seus editais estejam no topo do Qualis.

\section{Analisando os dados}

Segundo os objetivos traçados pela pesquisa, fixamos como objeto de análise o QualisPeriódicos, da área da Educação, trabalhando com as constantes transformações sofridas pelo indicador rumo a diminuir as diferenças entre os critérios das diversas áreas de avaliação e rumo à internacionalização da produção científica nacional. Metodologicamente, tratou-se de explicar e descrever os fenômenos que envolveram o objeto de estudo, identificando fatores determinantes e pressupostos (GIL, 2002), com instrumentos de pesquisa comparativos, avaliando similaridades e dessemelhanças (GIL, 2008). A principal fonte de dados foi a documentação oficial da CAPES (MARCONI; LAKATOS, 2002).

Os dados se referem aos períodos avaliativos do triênio de 2010-2012, momento de tendência à internacionalização amena; o quadriênio 2013-2016, quando se busca a internacionalização com maior rigor; e a avaliação de meio termo (2017-2018), quando internacionalizar passa a significar encontrar um índice de impacto. Coletados, os resultados da aplicação dos critérios foram transformados em gráficos para facilitar as análises.

Toda a discussão observada no triênio 2010 a 2012 resulta em um conjunto de orientações que busca se afastar da determinação de um fator de impacto que pudesse, como 
critério único, orientar a avaliação da produção científica publicada em periódicos. Havia uma orientação para a internacionalização, mas que se concretizava em exigir das revistas um corpo editorial internacionalizado, pareceristas que fossem filiados a instituições internacionais e um percentual de artigos com autores estrangeiros. Como já existia um movimento pela diversidade institucional dos veículos de divulgação científica, é possível perceber movimentos de cooperação com grupos internacionalizados.

Embora já houvesse um incentivo à indexação das revistas, a partir do quadriênio 20132016, os estratos superiores do Qualis passaram a exigir quantidades numéricas de determinados indexadores: Web of Science; Scopus; Scielo BR; Educ@; Social Sciences Citation Index; Redalyc; DOAJ; IRESIE; BBE; Latindex e Clase. Na avaliação de meio-termo (2017-2018), o critério de número de indexadores permanece, só que para o estrato A1 eles passam a ser mais restritos: Web of Science; Scopus e Scielo BR. Ao mesmo tempo, um indicador de impacto é utilizado pela primeira vez: o h5 do Google Scholar.

Ao lado dos indicadores mais rígidos, boas práticas de editoração passaram a ser valorizadas na classificação do triênio 2013-2016, tais como: artigos cadastrados no sistema DOI (Digital Object Identifier), composto por uma série de números e letras que identificam e legitimam a publicação; a modalidade de publicação ahead of print, que dá agilidade na publicação e aumenta o tempo de exposição do artigo para citações, possibilitando que o material aprovado ganhe divulgação e companha posteriormente um número publicado em fascículo; edições com baixa endogenia e alta proporção de artigos em língua estrangeira ou, mais especificamente, inglesa. Quanto à classificação de meio termo (2017-2018), aprofundouse a questão das boas práticas editoriais - qualidade gráfica, transparência na gestão editorial e na série histórica do periódico - e passou-se a exigir a identificação Orcid (Open Researcher and Contributor ID) dos autores.

A comissão de avaliação de periódicos educacionais do quadriênio 2013-2016 (CAPES, 2017) observou que houve inclusão de indexadores nos critérios de estratificação porque na classificação anterior revistas A1 ou A2 necessitavam estar indexadas no Scielo, medidor considerado muito restritivo. Em verdade, no triênio 2010-2012 não havia nenhuma exigência quanto a indexadores específicos. Com relação aos demais critérios, a avaliação 2013 e 2017 manteve-se inalterada. Até 2016, os periódicos eram classificados com base nas travas obrigatórias que determinavam que $25 \%$ deveria ser A1 + A2, sendo que A1 deveria ser menor que A2; $25 \%$ deveria ser B1 e 50\% estavam direcionados aos estratos: B2, B3, B4 e B5 (CAPES, 2021). Para a classificação 2017-2020 - e para a análise feita em 2019, considerando 
o período 2017 e 2018 - há uma reorganização dos estratos, como dissemos, e se propõe que $\mathrm{A} 1<\mathrm{A} 2 ; \mathrm{A} 1+\mathrm{A} 2<\mathrm{A} 3+\mathrm{A} 4 ; \mathrm{A} 1+\mathrm{A} 2+\mathrm{A} 3+\mathrm{A} 4 \leq 50 \%$, assim, os demais periódicos estariam nos estratos B1, B2, B3 e B4. Aqueles que não fossem considerados revistas científicas estariam no estrato C (CAPES, 2019).

A partir de todas estas alterações - seja nos critérios de indicadores, seja nos mais recentes padrões de estruturação: Qualis referência para cada área mãe e nova estratificação é possível visualizar e comparar o impacto dessa alteração na classificação dos periódicos no Tabela 1.

Tabela 1: Comparativo da quantidade de periódicos avaliados pelo Qualis-Periódicos Educação 2010-2012, 2013-2016 e 2017-2018.

\begin{tabular}{lccccc} 
Estratos & $\begin{array}{c}\text { Qualis-Periódico } \\
\text { Educação 2010- } \\
2012(\mathrm{a})\end{array}$ & $\begin{array}{c}\text { Qualis-Periódico } \\
\text { Educação 2013- } \\
2016(\mathrm{~b})\end{array}$ & $\begin{array}{c}\text { Qualis-Periódico } \\
\text { Educação 2017- } \\
2018(\mathrm{c})\end{array}$ & $\begin{array}{c}\text { Diferença entre a } \\
\text { e b }\end{array}$ & $\begin{array}{c}\text { Diferença entre b } \\
\text { e c }\end{array}$ \\
\hline A1 & 115 & 121 & 37 & +6 periódicos & -84 periódicos \\
\hline A2 & 170 & 380 & 39 & +210 periódicos & -341 periódicos \\
\hline A3 & Não possuía & Não possuía & 47 & & +47 periódicos \\
\hline A4 & Não possuía & Não possuía & 65 & & +65 periódicos \\
\hline B1 & 322 & 542 & 74 & +223 periódicos & -468 periódicos \\
\hline B2 & 378 & 425 & 89 & +47 periódicos & -336 periódicos \\
\hline B3 & 390 & 357 & 62 & +33 periódicos & -295 periódicos \\
\hline B4 & 455 & 307 & 115 & +148 periódicos & -192 periódicos \\
\hline B5 & 485 & 782 & Não possui & +297 periódicos & -782 periódicos \\
\hline Total & 2315 & 2914 & 528 & +599 periódicos & -2386 periódicos
\end{tabular}

Fonte: Elaboração dos autores a partir dos Relatórios Qualis-Periódicos Educação 2013, 2017 e 2019.

É possível observar que muitos periódicos conseguiram melhor classificação durante o quadriênio 2013-2016, mesmo com exigências mais objetivas, com critérios que passaram a ser mais específicos. No entanto, muitos periódicos desapareceram do conjunto avaliado em Educação, no meio termo (2019): com a ideia da área mãe, foram avaliados em outras áreas do 
conhecimento. Nesse sentido, o Gráfico 1 ilustra o impacto da medida para periódicos classificados nos estratos A1 e A2, estratos que identificam os melhores periódicos no transcorrer de todo o período 2010 a 2018.

Gráfico 1: Comparação entre os estratos A1 e A2 na classificação do triênio 2010-2012; quadriênio 2013-2016 e meio termo 2017-2018

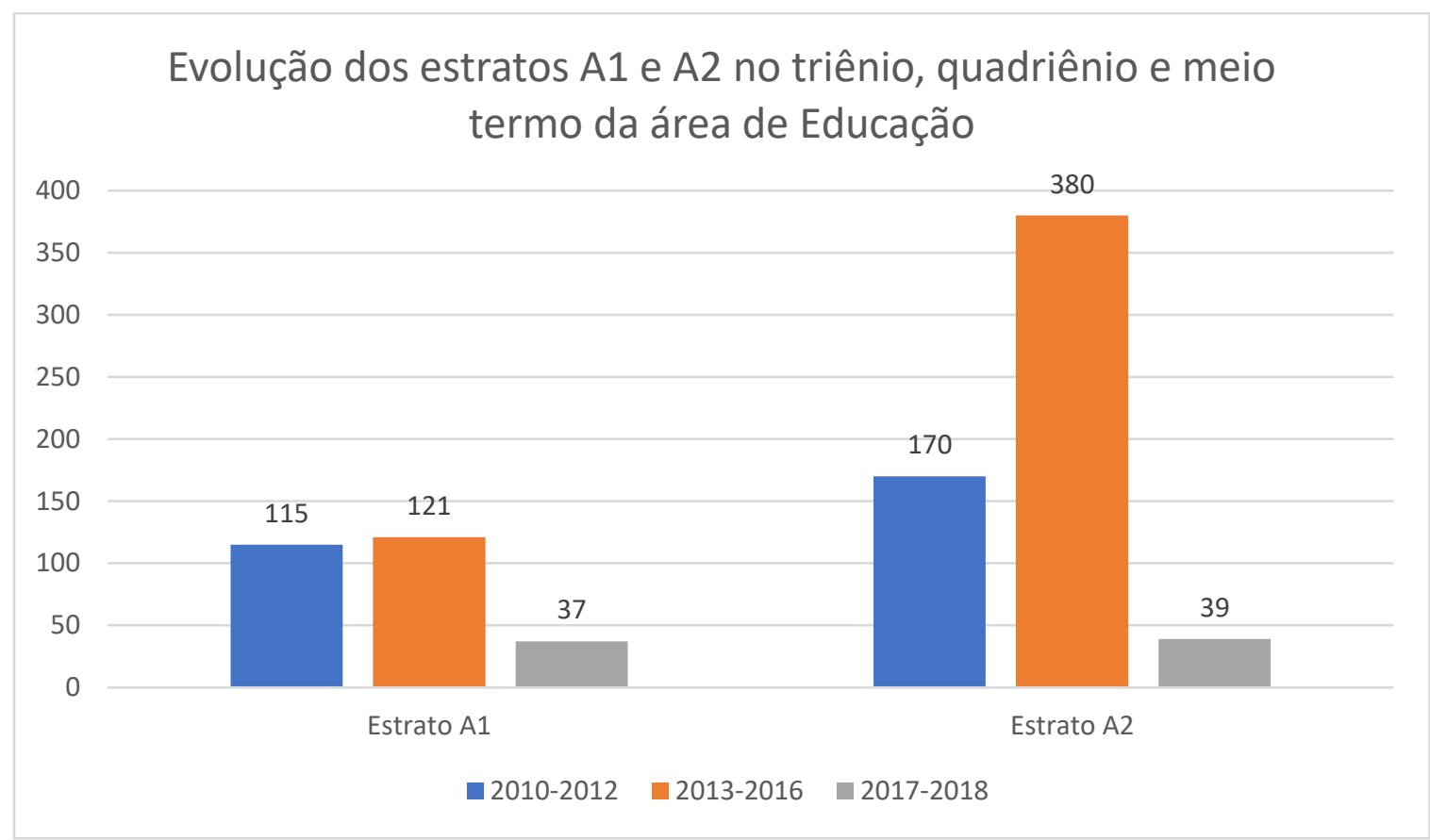

Fonte: Elaboração dos autores a partir dos Relatórios Qualis-Periódicos Educação 2013, 2017 e 2019.

Vale lembrar que na avaliação de meio termo (2017 e 2018) foi utilizado, para a área de Educação, o índice h (PUCRS, 2019) do Google Scholar, como medidor de impacto, ou de citação. A escolha recaiu sobre este indicador já que os periódicos nacionais de humanidades têm baixa presença nas bases Scopus e Web of Science. Dessa forma, para a avaliação realizada em 2019 foi aceito o cálculo de impacto pelo h 5 do Google Scholar, enquanto se discute no Colégio de Humanidades um método padrão de avaliação para o final do atual quadriênio (2017-2020), aproximando metodologia utilizada por todas as áreas (CAPES, 2021).

Para a avaliação final do quadriênio 2017 a 2020, haverá ainda um recorte linguístico para a utilização do h index: o idioma predominante do periódico passa a separar as revistas nacionais das demais, ou seja, atende-se à diferença, por exemplo, entre uma revista predominantemente constituída por artigos em português - que deve atender ao h 5 - e outra constituída por artigos em inglês - que deve atender ao Fator de Impacto. O h 5 dos periódicos 
nacionais passam a ser corrigidos pelo software Harzing's Publish or Perish. Determinou-se, também, que periódicos com o $\mathrm{h}$ index igual a zero ficariam classificados em $\mathrm{C}$, sendo que os demais estratos foram divididos em oito grupos com a média de 12,5\% por grupo, em que o mais elevado era aquele com maior $\mathrm{h}$ index (CAPES, 2021).

Resumindo, na avaliação proposta para o quadriênio 2017 a 2020, além dos periódicos serem avaliados por suas áreas mãe ou irmãs, serão classificados conforme seu impacto, pelo idioma em que publicam, diminuindo consideravelmente o número de revistas avaliadas e, portanto, diminuindo as revistas dos estratos A1 e A2, criando alta expectativa sobre os resultados do Qualis 2021.

\section{Conclusão}

Por tudo que foi dito, configura-se a importância do Qualis-Periódicos para a avaliação da produção docente vinculada aos programas de Pós-graduação stricto sensu, no Brasil. Mesmo assumindo muitas funções para as quais não foi criado, o instrumento permanece influenciando a direção de pesquisas científicas e interferindo em todo o campo editorial, uma vez que induz práticas de como o conhecimento científico de qualidade deve ser publicado (FRIGERI; MONTEIRO, 2014).

Assim, a análise comparativa dos dados sobre as classificações feitas nos três períodos - no triênio 2010-2012, no quadriênio 2013-2016 e na avaliação de meio termo (2017 e 2018) - demonstra que mudanças de critérios entre o primeiro e o segundo período tornaram a classificação mais objetiva, facilitando a estratificação dos periódicos e melhorando a posição relativa de muitos deles. Diferentemente, a transição de 2013-2016 para 2017-2018 foi realizada com um novo diferenciador - um medidor de impacto - que embora não tenha sido utilizado como fator único, criou condições para conduzir a próxima avaliação (2021).

Restam avaliar os efeitos da mudança, justamente, em 2021. O h index veio para ficar e seus efeitos serão materializados, enquanto equipes editoriais passam a se preocupar com a possibilidade de diálogo após a classificação e coordenadores de Pós-graduação passam a se preocupar com os efeitos da avaliação da produção docente no resultado da avaliação dos programas. Toda a comunidade científica, porém, olha com preocupação para a pontuação Qualis, já que esta orienta escolhas em outras agências, como quando um docente pede uma Bolsa de Pesquisador ao CNPq.

Embora seja possível pensarmos que parâmetros de avaliação como o Qualis-Periódicos sejam recentes - a série histórica montada para este artigo conta nove anos - e que os critérios 
ainda estejam em uma fase incremental, não é assim: por um lado, 2021 trará uma ruptura, um novo medidor, abandonando a tendência incremental; por outro lado, percebe-se um movimento dentro dos setores de avaliação para a extinção do Qualis. É preciso compreender e refletir mais sobre o sistema de avaliação de periódicos e sobre os indicadores que valorizam a produção docente no país, afastando os interesses particulares de grupos de interesse ou de indivíduos que desejam nortear a pesquisa brasileira.

\section{Referências}

AZEVEDO, Mário Luiz Neves; OLIVEIRA, João Ferreira de; CATANI, Afrânio Mendes. O Sistema Nacional de Pós-graduação (SNPG) e o Plano Nacional de Educação (PNE 20142024): regulação, avaliação e financiamento. Revista Brasileira de Política e Administração da Educação, v. 32, p. 783-803, 2016. Disponível em: https://seer.ufrgs.br/rbpae/article/view/68576. Acesso em: 01 abr. 2021.

BARRADAS BARATA, Rita de Cássia. Dez coisas que você deveria saber sobre o Qualis. Revista Brasileira de Pós-Graduação, v. 13, n. 30, 22 dez. 2016. Disponível em: http://ojs.rbpg.capes.gov.br/index.php/rbpg/article/view/947. Acesso em: 02 abr. 2021. BIZELLI, José Luís. Internacionalización: reflexiones a partir de la experiencia de un programa de postgrado en Educación Escolar brasileña. In: MARTÍN BRIS, Mario; JABONERO BLANCO, Mariano. (org.) Internacionalización de la educación en Iberoamérica: reflexiones y proyecciones. Madrid: Ed Santillana/UAH, 2017. p. 35-41. BIZELLI, José Luís; SANTOS CRUZ, José Anderson. Educación e Internacionalización: competencia o colaboración? In: MARTIN BRIS, Mario (org.). Internacionalización de la educación superior en Iberoamérica: miradas y perspectivas. Alcalá de Henares: Servicio de publicaciones de la Universidad de Alcalá de Henares. 2016. v. 01, p. 77-90.

BIZELLI, José Luís; SANTOS CRUZ, José Anderson. Indexadores internacionais para medir a produção docente na área de educação. In: LAMOTHE ZAVALETA, Carlos; ÁLVAREZ, María Cristina; MARTÍN BRIS, Mario. (org.). Práctica docente: experiencias, reflexiones y propuestas desde Iberoamérica. Veracruz: Universidad Veracruzana/México Academia Journals, 2019. v. 1, p. 137-148.

BLOG: Entenda a modalidade de publicação Ahead of Print (AOP). Periódicos de Minas, 2018b. Disponível em: https://www.periodicosdeminas.ufmg.br/entenda-a-modalidade-depublicacao-ahead-of-print-aop/. Acesso em: 03 abr. 2021.

BLOG: O que é DOI? Periódicos de Minas, 2018a. Disponível em: https://www.periodicosdeminas.ufmg.br/o-que-e-doi/. Acesso em: 03 abr. 2021. BLOG: O que é Orcid? Periódicos de Minas, 2018c. Disponível em: https://www.periodicosdeminas.ufmg.br/o-que-e-orcid/. Acesso em: 03 abr. 2021. BRASIL. Ministério da Educação. CAPES: História e Missão. Brasília: MEC, 2020. Disponível em: https://www.gov.br/capes/pt-br/acesso-a-informacao/institucional/historia-emissao. Acesso em: 01 abr. 2021.

BRASIL. Ministério da Educação. CAPES: Sucupira. Brasília: MEC, 201?. Disponível em: https://sucupira.capes.gov.br/sucupira/. Acesso em: 01 abr. 2021.

CAPES. Ministério da Educação. Coordenação da Área de Educação na CAPES. Relatório de Avaliação 2010-2012 Trienal 2013: Educação. Brasília, MEC, 2013. 48 p.

CAPES. Ministério da Educação. Coordenação da Área de Educação na CAPES. Relatório da Avaliação Quadrienal 2017: Educação. Brasília: MEC, 2017. 93 p.

CAPES. Ministério da Educação. Coordenação da Área de Educação na CAPES. Relatório do Qualis Periódicos: Área 38, Educação. Brasília: MEC, 2019. 11 p. 
CAPES. Ministério da Educação. Coordenação da Área de Educação na CAPES. Notas sobre o qualis periódicos: área de educação. Brasília: MEC, 2021. Disponível em:

https://sbhe.org.br/uploads/information_files/8/56a8d7de9cf0ec0f9ce831af2d11ba3d.pdf.

Acesso em: 01 abr. 2021.

CARIBÉ, Rita de Cássia do Vale. Comunicação científica: reflexões sobre o conceito. Informação \& Sociedade: estudos, João Pessoa, v. 25, n. 3, p. 89-104, 28 dez. 2015. FRIGERI, Mônica; MONTEIRO, Marko Synésio Alves. Qualis periódicos: indicador da política científica no Brasil? Estudos de Sociologia, v. 19, n. 37, p. 299-315, 2014. Disponível em: https://periodicos.fclar.unesp.br/estudos/article/view/6266. Acesso em: 31 mar. 2021. GIL, Antônio Carlos. Como elaborar projetos de pesquisa. 4. ed. São Paulo: Atlas, 2002. GIL, Antônio Carlos. Métodos e técnicas de pesquisa social. 6. ed. São Paulo: Atlas, 2008. MARCONI, Marina de Andrade; LAKATOS, Eva Maria. Técnicas de pesquisa: planejamento e execução de pesquisas, amostragens e técnicas de pesquisas, elaboração, análise e interpretação de dados. 5. ed. São Paulo: Atlas, 2002.

MONTEIRO, Adriano Lisboa; FURLAN, Maysa; SUAREZ, Paulo Anselmo Ziani. Sistema nacional de pós-graduação e a área de química na CAPES. Quím. Nova, v. 40, n. 6, p. 618625, jul. 2017. Disponível em: http://www.scielo.br/scielo.php?cript=sci_arttext\&pid=S010040422017000600618\&lng=en\&nrm=iso. Acesso em: 28 mar. 2021.

NATURE INDEX. 2021. Disponível em: https://www.natureindex.com/countryoutputs/Brazil. Acesso em: 29 mar. 2021.

PEREZ, Olivia Cristina. O novo Qualis Periódicos: Possíveis diretrizes, Impactos e resistências. Novos Debates - Fórum de Debates em Antropologia, v. 6, p. 1-8, 2020.

Disponível em: http://novosdebates.abant.org.br/e6212/. Acesso em: 03 abr. 2021.

PONCE, Branca Jurema et al. Sobre a melhoria da produção e da avaliação de periódicos científicos no Brasil. Ensaio: aval.pol.públ.Educ., Rio de Janeiro, v. 25, n. 97, p. 1032-1044, dec. 2017. Disponível em: http://www.scielo.br/scielo.php?script=sci_arttext\&pid=S010440362017000401032\&lng=en\&nrm=iso. Acesso em: 31 mar. 2021.

PUCRS. Índice h. Porto Alegre, 05 jul. 2019. Disponível em:

https://biblioteca.pucrs.br/apoio-a-pesquisa/bibliometria/indice-h/. Acesso em: 03 abr. 2021. RIBEIRO, Daniele Alves; ALENCAR, Maria do Socorro Nunes Macedo; COUTO, Euclides de Freitas. Critérios Qualis A1 da Educação: a avaliação sob a perspectiva da disputa acadêmica. Linhas Críticas (UnB), v. 22, n. 47, p. 229-248, 2016. Disponível em: https://periodicos.unb.br/index.php/linhascriticas/article/view/4816. Acesso em: 28 mar. 2021.

SANTOS CRUZ, José Anderson. Gestão do conhecimento e gestão editorial: qualificadores da avaliação de periódicos da área de educação. 2020. 282 f. Tese (Doutorado em Educação Escolar) - Faculdade de Ciências e Letras, Universidade Estadual Paulista, Araraquara, SP, 2020.

SANTOS CRUZ, José Anderson; SANTOS, Gildenir Carolino; BIZELLI, José Luís. Fatores de qualificação e boas práticas nos periódicos brasileiros em educação: indexação versus fator de impacto. In: SANTOS, Gildenir Carolino; MARTINS, Valéria dos Santos Gouveia. (org.). Ciência aberta, sistemas e ambientes de informação: do acesso às boas práticas de pesquisa. Campinas: Unicamp, 2019. v. 1, p. 239-2631.

SILVA, Antonio Ozaí da. Sua revista tem Qualis. Revista Mediações (UEL), v. 14, n. 1, p. 117-124, 2009. Disponível em:

http://www.uel.br/revistas/uel/index.php/mediacoes/article/view/3350. Acesso em: 01 abr. 2021.

SOUZA, Ângelo Ricardo de. et al. Qualis: a construção de um indicador para os periódicos na área da Educação. Práxis Educativa, v. 13, n. 1, p. 219-231, 2018. Disponível em: 
https://www.researchgate.net/publication/324839153_Qualis_a_construcao_de_um_indicador _para_os_periodicos_na_area_da_Educacao. Acesso em: 28 mar. 2021.

YAMAMOTO, Oswaldo Hajime. Vale a pena avaliar periódicos científicos? Estud. psicol. (Natal), Natal, v. 6, n. 2, p. 129-131, 2001. Disponível em:

http://www.scielo.br/scielo.php?script=sci_arttext\&pid=S1413-

294X2001000200001\&lng=en\&nrm=iso. Acesso em: 31 mar. 2021.

\section{SOBRE O/AS AUTOR/AS}

Laís Zaccaro Sene. Mestranda, Faculdade de Ciências e Letras (FCLAr/UNESP) - Brasil; Programa de Pós-Graduação em Educação Escolar. Lattes: http://lattes.cnpq.br/1359753390714803.

José Luís Bizelli. Livre docente, Faculdade de Ciências e Letras (FCLAr/UNESP) - Brasil; Programa de Pós-Graduação em Educação Escolar. Pesquisador Bolsista de Produtividade em Pesquisa $2-$ CNPq. Coordenador Nacional FEPAE. Lattes: http://lattes.cnpq.br/3751287338655685.

\section{Como citar este artigo (ABNT):}

SENE, Laís Zaccaro; BIZELLI, José Luís. Sistema de avaliação de periódicos no Brasil: impactos da evolução dos critérios do qualis-periódicos da área de educação. Revista Práxis $\begin{array}{lllllll}\text { Educacional, Vitória da Conquista, v. } & \text { 18, } & \text { n. } & 4922 .\end{array}$ https://doi.org/10.22481/praxisedu.v18i49.9388 